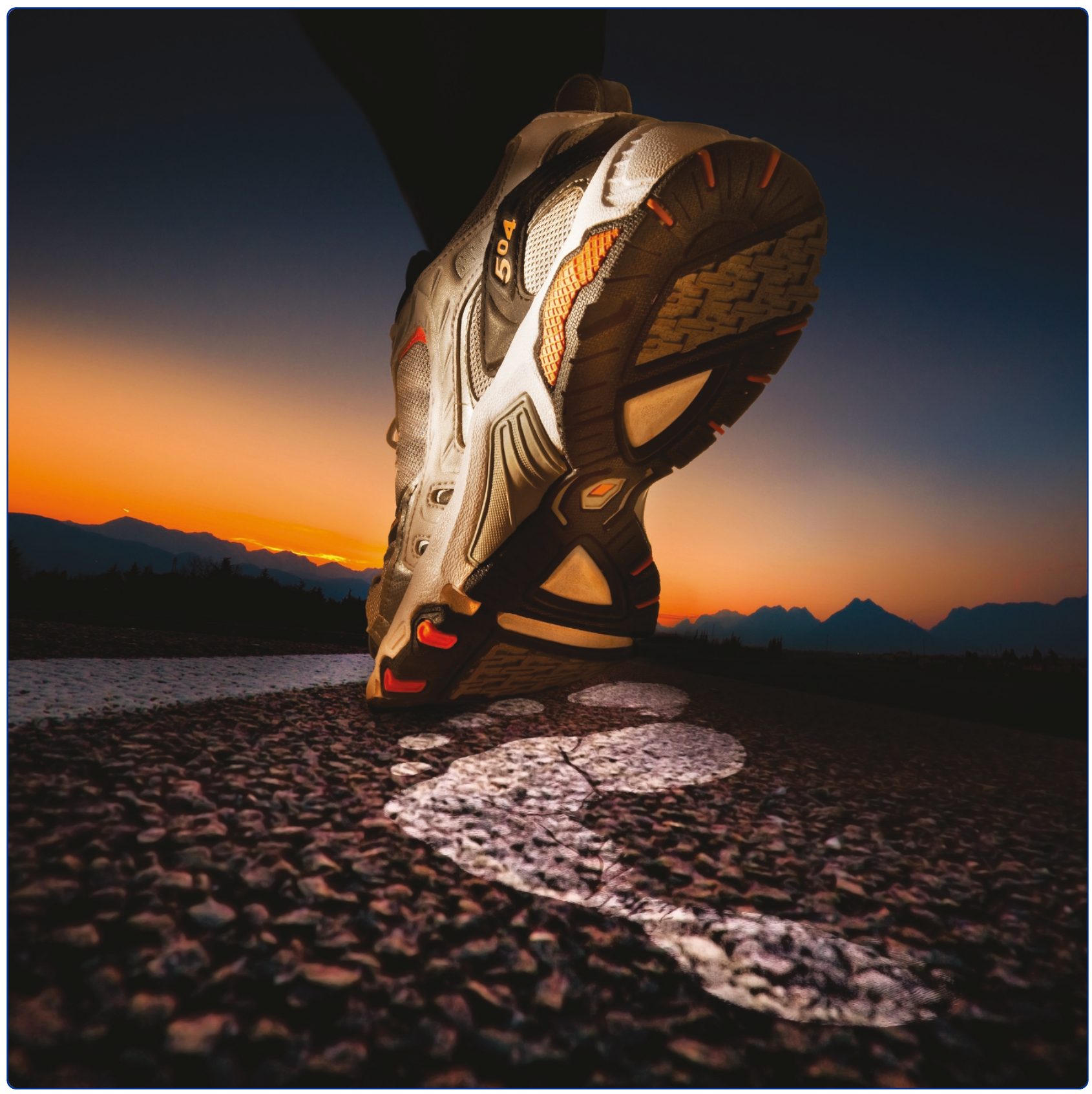

\title{
Setting the pace: the 2011 Australasian Podiatry Council conference
}

Menz and Firth 


\title{
Setting the pace: the 2011 Australasian Podiatry Council conference
}

\author{
Hylton B Menz ${ }^{1 *}$ and Julia Firth ${ }^{2}$
}

\begin{abstract}
The 2011 Australasian Podiatry Council conference was held from April 26 to 29 in Melbourne, Victoria, Australia. This commentary provides a brief overview of the conference, including the speakers and topic areas covered, selected original research highlights, and award winning presentations.
\end{abstract}

\section{Background}

The 2011 Australasian Podiatry Council conference (APC2011) was held at the Melbourne Exhibition and Convention Centre from April 26 to 29, and attracted over 1,000 delegates. The purpose of this commentary paper is to provide an overview of the conference, including the speakers and topic areas covered, selected original research highlights and award winning presentations.

\section{Speakers and topics covered}

APC2011 featured three international keynote speakers Professor Andrew Boulton (University of Manchester, UK), Professor Irene Davis (Harvard University, USA) and Dr Edward Roddy (Keele University, UK) - and 10 invited speakers (see Table 1). The speakers attracted considerable media attention, and interviews with Prof Irene Davis and Trevor Prior conducted during the conference can now be viewed at the JFAR YouTube channel [1].

In addition to the keynote and invited speaker presentations, a total of 158 free papers were submitted for consideration - the largest number of submissions ever received for an Australasian podiatry conference. A breakdown of abstracts by topic area is shown in Figure 1, which highlights the dominance of research activity in the fields of the high risk foot management and foot and ankle biomechanics. Of these abstracts, 54 were accepted for oral presentation and 61 for poster presentation. Each of these abstracts can be freely downloaded as html text or as a PDF file at the JFAR website [2]. Of particular note, the conference program featured the largest number of

\footnotetext{
* Correspondence: h.menz@latrobe.edu.au

${ }^{1}$ Musculoskeletal Research Centre, Faculty of Health Sciences, La Trobe

University, Bundoora, Victoria, Australia

Full list of author information is available at the end of the article
}

presentations of systematic reviews [3-8] and randomised trials [9-13] indicating the increasingly high quality of research being conducted in Australasia.

APC2011 also saw the introduction of 'virtual' poster displays using flat-screen monitors, which enabled the presentation of substantially more posters than the traditional hard copy approach. Photos from the conference are provided in Figures 2, 3, 4 and 5.

\section{Selected original research highlights}

APC2011 featured more original research papers than any previous Australasian podiatry conference. Selected research findings for each of the conference theme areas are provided below.

\section{High risk foot}

- Hospital separations for diabetes-related foot disease in Victoria, Australia, vary according to the degree of socioeconomic disadvantage of each local government area [14]

- Standardising diabetic foot management by instituting multi-disciplinary teams, clinical pathways, telehealth support and surveys resulted in a $64 \%$ reduction in amputation rates and a $24 \%$ reduction in average length of stay in Queensland hospitals [15]

\section{Rheumatology}

- Ultrasound-guided injection of dexamethasone is more effective than placebo (sterile saline) in the treatment of plantar fasciitis [11]

- Intra-articular injection of hyaluronan $\left(\right.$ Synvisc $^{\circledR}$, hylan G-F 20) is no more effective than placebo (sterile saline) in the treatment of pain associated 


\section{Table 1 Invited speakers}

\begin{tabular}{ll}
\hline Speaker & Institution \\
\hline Dr Harvinder Bedi & Orthosports Victoria, Melbourne \\
Prof Peter Brooks & Australian Health Workforce Institute, Melbourne \\
Dr Kay Crossley & University of Melbourne \\
Dr George Koulouris & Melbourne Radiology Clinic \\
Dr Stephen Marty & Monash University/Pharmacy Board of Australia \\
A/Prof Bill McGuiness & La Trobe University, Melbourne \\
Trevor Prior & Premier Podiatry, London, UK \\
Dr Monique Ryan & Royal Children's Hospital, Melbourne \\
A/Prof Jonathan & Baker IDI Heart and Diabetes Institute, \\
Shaw & Melbourne \\
Jason Warnock & Podiatry Board of Australia \\
A/Prof Scott Wearing & Bond University, Queensland \\
\hline
\end{tabular}

with first metatarsophalangeal joint osteoarthritis [13]

\section{Gerontology}

- A multifaceted podiatry intervention consisting of foot orthoses, footwear advice and a foot and ankle exercise program can reduce falls by $36 \%$ in older people [12]

\section{Paediatrics}

- Traditional school shoes restrict children's foot motion during walking, particularly at the midfoot, during the contact period and propulsion phases of gait [16]

- A 'Toe-Walking Tool' has been developed and validated as a comprehensive way to assess children with idiopathic toe-walking and to assist in appropriate referral [17]

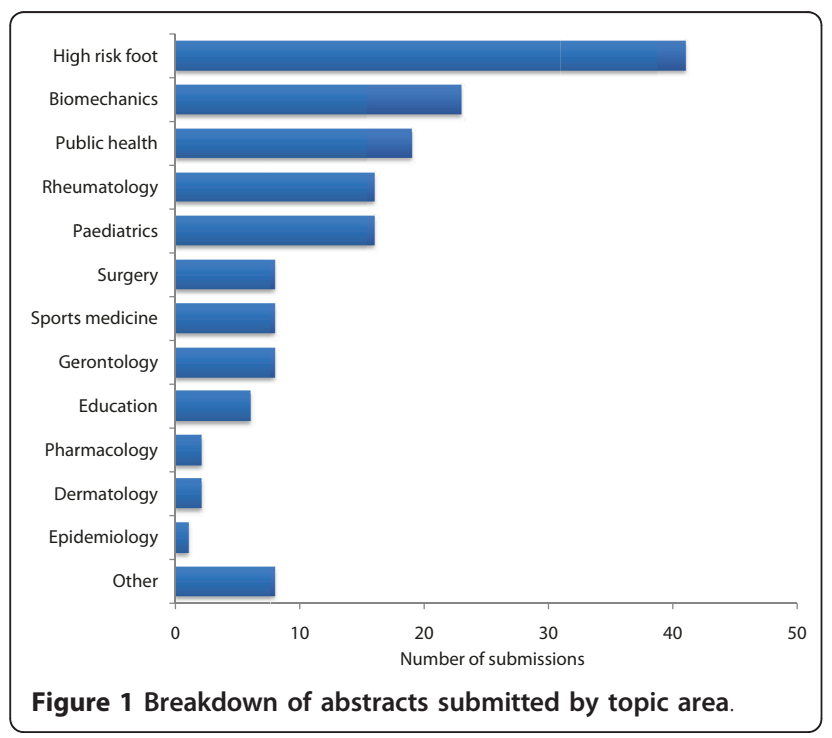

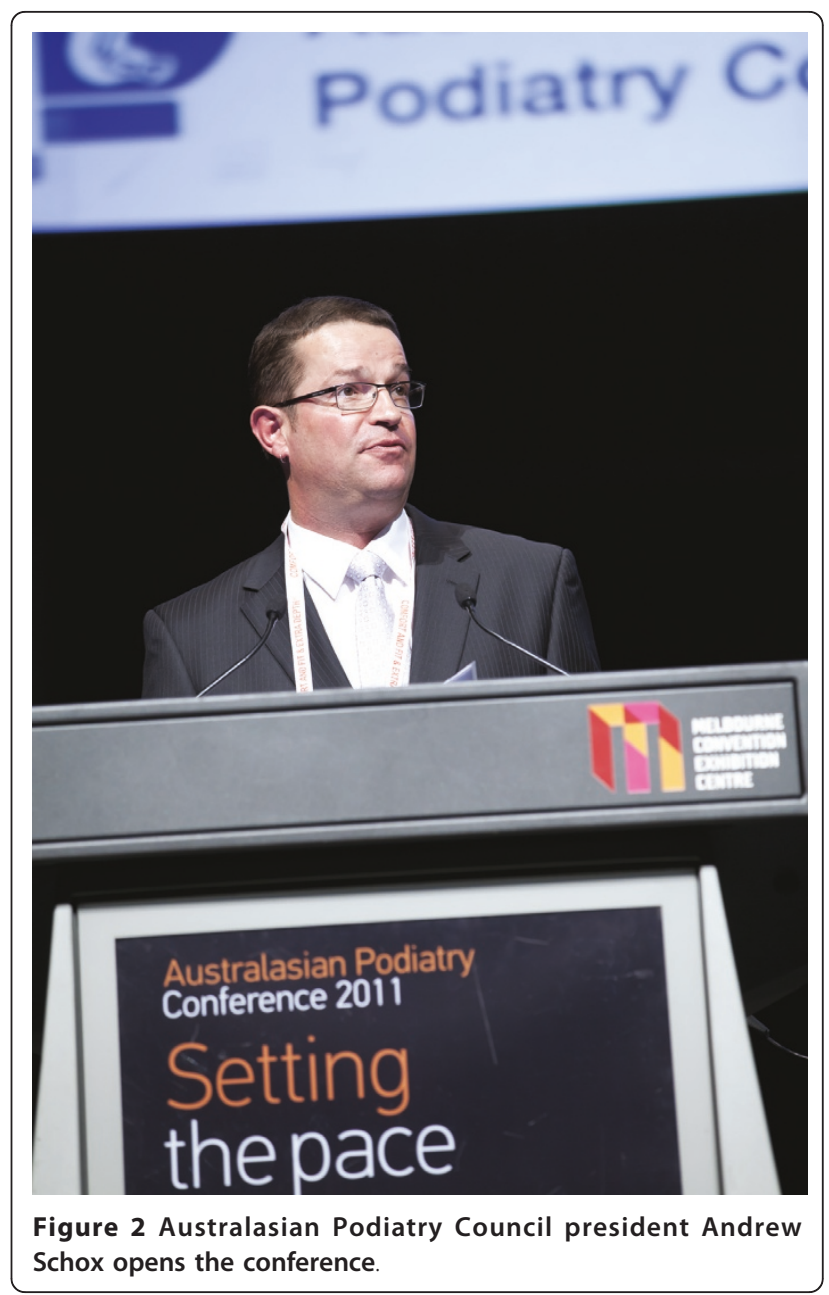

\section{Biomechanics and foot orthoses}

- Increasing plantar sensory feedback to the medial aspect of the foot reduces midfoot pronation during walking [18]

- Lateral wedged insoles are no more effective than flat inserts in the treatment of medial compartment knee osteoarthritis [9]

\section{Wound management}

- A one-year audit of microbiology culture results in a high risk foot clinic indicated a surprisingly high incidence of Methicillin-resistant Staphylococcus aureus (16\% of patients) [19]

- Negative pressure wound therapy achieves complete wound closure in $60 \%$ of patients with postsurgical wounds and is associated with a lower rate of major amputation [20]

\section{Surgery}

- A meta-analysis of 24 studies indicates that the scarf osteotomy produces a marginally greater 


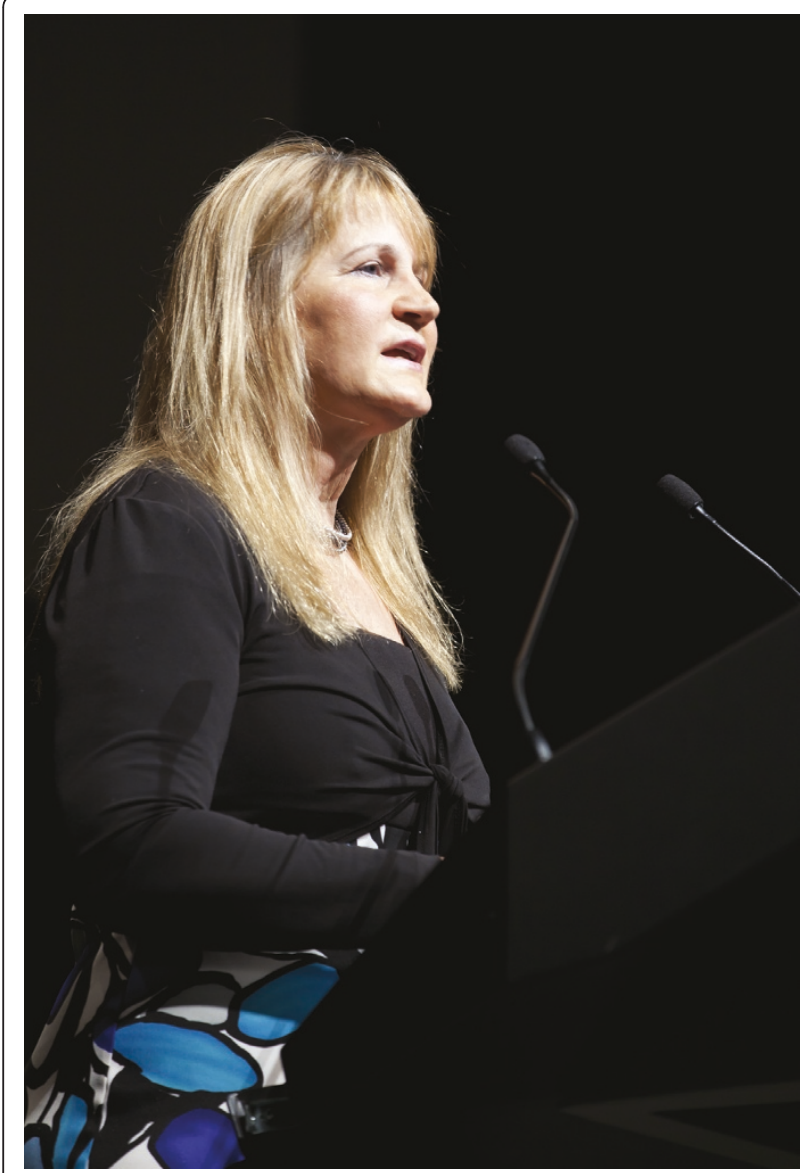

Figure 3 Keynote speaker Professor Irene Davis

reduction in the 1-2 intermetatarsal angle in patients with hallux valgus compared with the chevron osteotomy [5]

\section{Conference award winners}

The APC2011 Conference Awards Committee consisted of Dr Karl Landorf (Chair), Dr Angela Evans, Mario Horta and Prof Keith Rome. Four awards were presented at the conference: (i) the JFAR Best Paper Award, (ii) the Best New Investigator Award, (iii) the Best NonResearch Paper Award and (iv) the Best Research Poster Award. A summary of the award-winning presentations is provided below, and abstracts of each of the awardwinning presentations can be downloaded at the JFAR website by following the relevant links in the reference list.

\section{JFAR Best Paper Award}

This was awarded to Dr Shan Bergin, Southern Health, for her presentation "Diabetes related foot disease: know thine enemy" [14]. This paper highlighted the fact that

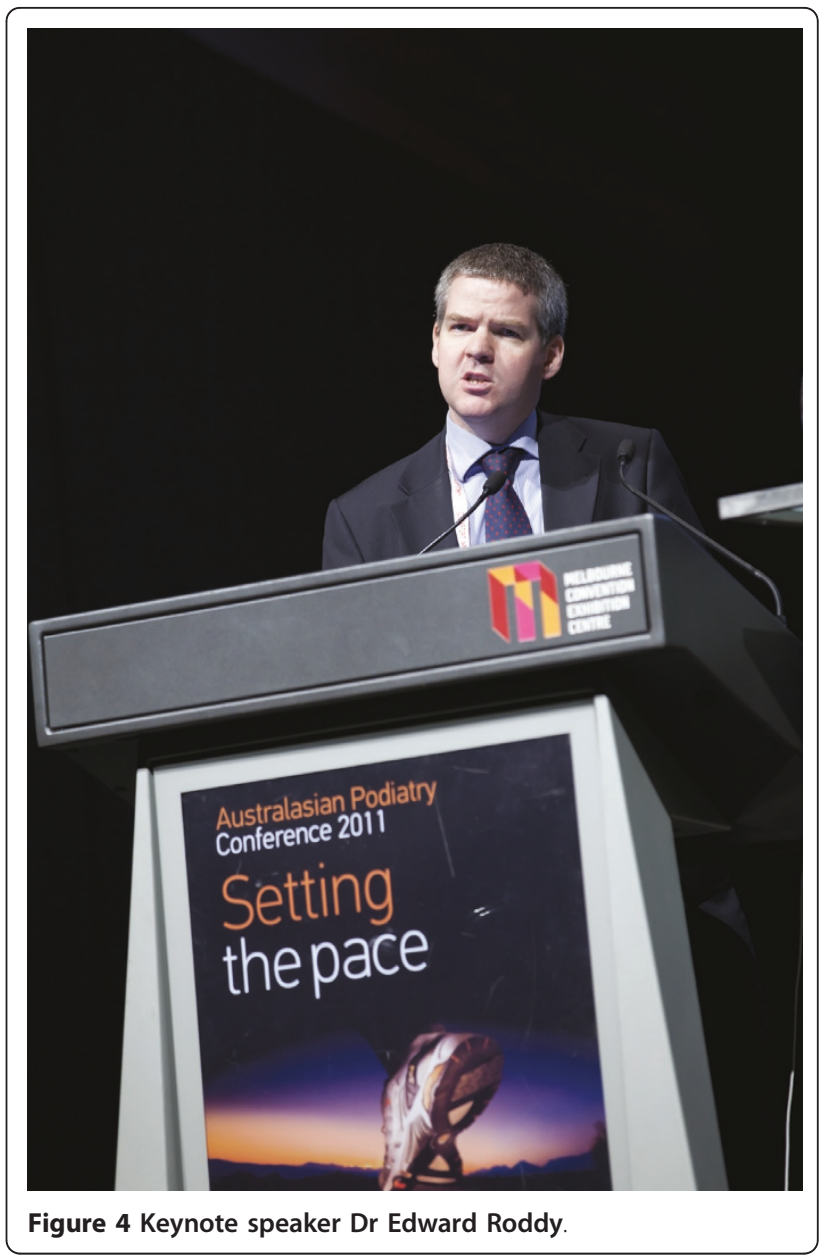

significant numbers of people in Victoria with diabetes suffer from neuropathy, PVD, ulcers and amputation, and that the socio-economic status of patients' local area can have a significant impact on clinical outcomes. A full paper based on this presentation has recently been published in JFAR [21].

\section{Best New Investigator Award}

This was awarded to Dr George Murley, La Trobe University, for his presentation "Do foot orthoses change lower limb muscle activity in people with flat-arched feet towards a pattern observed in those with normalarched feet?" [22]. Derived from his recently published PhD studies, this presentation showed that the electromyographic (EMG) activity of lower limb muscles differs in people with flat feet, and that foot orthoses can alter these muscle activation patterns.

\section{Best Non-Research Paper Award}

This was awarded to Sylvia McAra, Charles Sturt University, for her presentation "Glyceryl trinitrate therapy for ischaemia, painful diabetic neuropathy, healing of foot ulceration and other podiatric conditions: a 


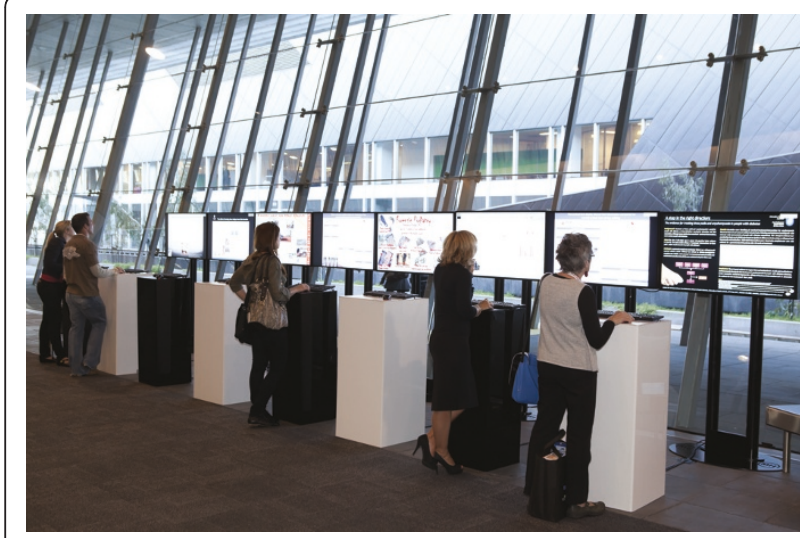

Figure $\mathbf{5}$ The virtual poster display area.

literature review" [23]. Glyceryl trinitrate is widely known to be a very effective vasodilator for the treatment of angina, but may also facilitate wound healing with a mechanism of action similar to hyperbaric oxygen therapy. This presentation provided a comprehensive overview of the topical application of this therapy for wound management.

\section{Best Research Poster Award}

This was awarded to Gordon Hendry and colleagues, Glasgow Caledonian University, for the poster "Foot related impairments and disability in juvenile idiopathic arthritis persist despite modern day treatment paradigms" [24]. This poster was based on a cross-sectional survey of foot related impairments and disability in patients with juvenile idiopathic arthritis, and showed that approximately two thirds of the sample had mild to moderate foot-related disability, despite being managed with disease modifying anti-rheumatics, anti-TNF drugs and specialist paediatric podiatry care.

\section{Summary}

APC2011 was a highly successful event that showcased the breadth and quality of clinical foot and ankle research being conducted in Australasia. The next Australasian podiatry conference will be hosted in Sydney in 2013.

\footnotetext{
Acknowledgements

Prof Hylton Menz was the Chair of the Scientific Committee and Julia Firth was the Chair of the Organising Committee for the Australasian Podiatry Council Conference. The authors would like the thank the Conference Organising Committee (Peter Lazzarini, Vice Chair; Dr Sue Whicker, Treasurer; Katrina Richards Marketing/Social Committee Chair; Chris Bishop, Sponsorship Chair; Joel Gurr, Committee Member; and George Wilson, Committee Member) and the Scientific Committee (Chris Bishop, Rachael Bradhurst, A/Prof Joshua Burns, Matthew Dilnot, Dr Angela Evans, Julia Firth, Joel Gurr, Mario Horta, Dr Karl Landorf, Dr Shannon Munteanu, Prof Keith Rome, and Dr Sue Whicker). We would also like to thank George Wilson for his assistance with the photographs.
}

\section{Author details}

${ }^{1}$ Musculoskeletal Research Centre, Faculty of Health Sciences, La Trobe University, Bundoora, Victoria, Australia. ${ }^{2}$ Podiatry Department, St Vincent's Hospital, Melbourne, Victoria, Australia.

\section{Authors' contributions}

HBM drafted the manuscript and JF provided feedback. Both authors read and approved the final manuscript.

\section{Competing interests}

The authors declare that they have no competing interests.

Received: 6 July 2011 Accepted: 15 July 2011 Published: 15 July 2011

\section{References}

1. Journal of Foot and Ankle Research YouTube channel. [http://www. youtube.com/JFootAnkleRes].

2. Proceedings of the Australasian Podiatry Council Conference 2011. [http://www.jfootankleres.com/supplements/4/S1].

3. Hawke F, Walter K, Chuter V, Burns J: Treating lower limb muscle cramps: a Cochrane systematic review. J Foot Ankle Res 2011, 4:017.

4. Munteanu SE, Barton CJ: Lower limb biomechanics during running in individuals with Achilles tendinopathy: a systematic review. J Foot Ankle Res 2011, 4:032.

5. Smith SE, Landorf KB, Menz HB: Chevron versus scarf osteotomy for 1-2 intermetatarsal reduction in the surgical treatment of hallux valgus: a systematic review and meta-analysis. J Foot Ankle Res 2011, 4:044.

6. Leitch SP, Bialocerkowski AE, Warden SJ, Collins NJ, Chien AW, Crossley KM: A systematic review and meta-analysis of conservative management of Achilles tendinopathy. J Foot Ankle Res 2011, 4:P32.

7. McMillan AM, Landorf KB, Barrett J, Menz HB, Bird AR: Diagnostic imaging for chronic plantar heel pain: a systematic review and meta-analysis. $J$ Foot Ankle Res 2011, 4:P40.

8. Zammit GV, Menz HB, Munteanu SE, Landorf KB, Gilheany MF: What is the best available evidence for treatment of first metatarsophalangeal joint osteoarthritis? J Foot Ankle Res 2011, 4:P61.

9. Bennell KL, Bowles K-A, Payne C, Cicuttini F, Williamson E, Forbes A, Hanna F, Davies-Tuck M, Hinman RS: Lateral wedge shoe insoles for medial knee osteoarthritis: a 12-month randomised controlled trial. $J$ Foot Ankle Res 2011, 4:07.

10. Landorf KB, Morrow AR, Spink MJ, Nash CL, Novak A, Bird A, Potter J, Menz HB: Effectiveness of scalpel debridement for painful plantar calluses in older people: a randomised trial. J Foot Ankle Res 2011, 4:023.

11. McMillan AM, Landorf KB, Gilheany MF, Bird AR, Morrow A, Menz HB: Ultrasound guided corticosteroid injection for plantar fasciitis: a randomised controlled trial. I Foot Ankle Res 2011, 4:029.

12. Spink MJ, Fotoohabadi MR, Wee E, Landorf KB, Hill KD, Lord SR, Menz HB: Efficacy of a multifaceted podiatry intervention to improve balance and prevent falls in older people: a randomised trial. J Foot Ankle Res 2011, 4: 047.

13. Zammit GV, Munteanu SE, Menz HB, Landorf KB, Handley CJ, ElZarka A, DeLuca J: Intra-articular hyaluronan (Synvisc(R), hylan G-F 20) for the treatment of first metatarsophalangeal joint osteoarthritis: a randomised, placebo controlled trial. J Foot Ankle Res 2011, 4:054.

14. Bergin SM, Brand CA, Colman PG, Campbell DA: Diabetes related foot disease; 'know thine enemy'. J Foot Ankle Res 2011, 4:08.

15. Lazzarini P, O'Rourke S, Russell A, Derhy P, Kamp M: Standardising practices improves ambulatory diabetic foot management and reduces amputations: the Queensland Diabetic Foot Innovation Project, 2006 2009. J Foot Ankle Res 2011, 4:025.

16. Wegener C, Smith R, Hunt A, Vanwanseele B, Greene A, Burns J: Children's rearfoot and midfoot motion while walking in school shoes. J Foot Ankle Res 2011, 4:049.

17. Williams C, Tinley P, Curtin M: The "Toe Walking Tool": a novel method of assessing toe walking children. J Foot Ankle Res 2011, 4:051.

18. Bartold S, Bryant A, Clark R, Paterson K, Ritchie C: Acute effects of a shoe with enhanced plantar sensory feedback on midfoot kinematics whilst walking. J Foot Ankle Res 2011, 4:O2.

19. White J, Toh L, Dickson HG, Koo EN, Winters GS, Harpur MG, Widdup J, Lau NS: Microbiology culture results in high risk foot clinic patients: an audit. J Foot Ankle Res 2011, 4:050. 
20. Veldhoen D, Nube V, Molyneux L: Are we doing better under pressure? An audit of post surgical wounds managed with negative wound pressure therapy. J Foot Ankle Res 2011, 4:048.

21. Bergin SM, Brand CA, Colman PG, Campbell DA: The impact of socioeconomic disadvantage on rates of hospital separations for diabetesrelated foot disease in Victoria, Australia. J Foot Ankle Res 2011, 4:17.

22. Murley GS, Landorf KB, Bird AR, Menz HB: Do foot orthoses change lower limb muscle activity in people with flat-arched feet towards a pattern observed in those with normal-arched feet? J Foot Ankle Res 2011, 4:033.

23. McAra S: Glyceryl trinitrate therapy for ischaemia, painful diabetic neuropathy, healing of foot ulceration and other podiatric conditions: a literature review. J Foot Ankle Res 2011, 4:028.

24. Hendry GJ, Gardner-Medwin J, Watt GF, Woodburn J, McColl JH, Sturrock RD: Foot related impairments and disability in juvenile idiopathic arthritis persist despite modern day treatment paradigms. $J$ Foot Ankle Res 2011, 4:P24.

doi:10.1186/1757-1146-4-20

Cite this article as: Menz and Firth: Setting the pace: the 2011

Australasian Podiatry Council conference. Journal of Foot and Ankle Research 2011 4:20.

\section{Submit your next manuscript to BioMed Central} and take full advantage of:

- Convenient online submission

- Thorough peer review

- No space constraints or color figure charges

- Immediate publication on acceptance

- Inclusion in PubMed, CAS, Scopus and Google Scholar

- Research which is freely available for redistribution

Submit your manuscript at www.biomedcentral.com/submit 